International Journal of Engineering \& Technology, 7 (3.9) (2018) 68-70
International Journal of Engineering \& Technology
SPC
Website: www.sciencepubco.com/index.php/IJET
Research paper

\title{
Sorption of Copper Metal Solution by Wetland Soil
}

\author{
Joshua Edwayne Liew ${ }^{1}$, Jee Khai Wong ${ }^{2 *}$, Ming Fai $\mathrm{Chow}^{2}$, Voon Chiet Chai ${ }^{3}$ \\ ${ }^{l}$ Department of Civil Engineering, College of Engineering, Universiti Tenaga Nasional (UNITEN), Malaysia. \\ ${ }^{2}$ Institute of Energy Infrastructure (IEI), Universiti Tenaga Nasional, Malaysia. \\ ${ }^{3}$ School of Energy, Geoscience, Infrastructure and Society (EGIS), Heriot-Watt University Malaysia. \\ *Corresponding author E-mail: Wongjk@ uniten.edu.my
}

\begin{abstract}
This study is to determine the equilibrium time and removal efficiency of copper by wetland soil. The wetland is located near the car park at College of Engineering, UNITEN. Wetland soil were collected randomly at a depth of $20 \mathrm{~cm}$ to $50 \mathrm{~cm}$. Soil samples are then oven dried at $105^{\circ} \mathrm{C}$ for 48 hours. After that it is let to cool down for 15 minutes before crushed and sieved through a $2.36 \mathrm{~mm}$ size sieve pan. Based on the Batch equilibrium method, the wetland soil is soaked in copper metal solution for different study time of $1,2,3,5,24$, 168 and 336 hours. Each studied time are prepared in three samples, with initial copper metal solution concentration $1 \mathrm{mg} / \mathrm{l}$. Parallel method is used in order to prevent disruption on the soil to solution ratio. Results obtained show that the concentration of copper metal solution decreases gradually and reached a constant during the period of 24 hours to 168 hours. Desorption phenomenon also occurred during that period of time. The removal percentage shows an increase up to $50 \%$. It clearly shows that adsorption of copper metal solution by wetland soil is effective.
\end{abstract}

Keywords: Copper metal solution removal; Heavy metal sorption; Wetland soil

\section{Introduction}

Water runoff can be a source of pollutant to the environment and water receivers. For example, water surface runoffs pollution occurs when rainwater or melting snow washes off roads, bridges, parking lots and other impermeable surfaces. In the case of road runoff, contaminants are mainly from vehicle exhaust, sandstorm dust, fuels, engine oil and grease, break and tyre wears which contains a variety of toxic components and are transported to receiving waters, lakes, water reservoir, wetlands and other types of water bodies (Gardiner et al., 2016). Typical pollutants in road runoffs are organic compounds, nutrients and heavy metals (Fronczyk, 2017). According to Gill et al., 2014 heavy metals are the most problematic pollutants because of their toxicity.

Heavy metals have high density and high atomic weight. Other than that, they cannot be biodegraded or destroyed. Heavy metals are accumulative in nature which causes its degree of concentration to increase (Wang et al., 2015). Some metals such as lead, zinc and copper have less toxicity but with the increase of concentration, it can be very harmful as well. Too much exposure can lead to serious long and short-term effects to the human body, some of them are high fever, lung cancer, stomach_ache, dizziness, organ failure and many more (Järup, 2003).

In order to reduce heavy metal concentration, researchers ((Nelson, 2002; Qasaimeh et al., 2015; Yao et al., 2012) had stated that adsorption by wetland soil is an effective and efficient way. Adsorption is a natural process where heavy metals are adsorbed by clay and organic matter through electrostatic attraction (Qasaimeh et al., 2015). It had been widely used and utilized as a treatment for heavy metal because it does not only creates green and recreational space but also economic friendly (Nelson, 2002). Other treatments such as soil replacement method, leaching, fixation, electrokinetic and other physicochemical treatments tend to be very tedious, ineffective, expensive, time-consuming and not to mention, not environmental friendly (Sree et al., 2016).

\section{Methodology}

In this study, time is used as the manipulating variable to determine the equilibrium time and removal efficiency of copper metal solution by wetland soil. Batch equilibrium method is selected to determine the time required for the wetland soil to reach the maximum capacity. Finally, flame method of Atomic Absorption Spectrometer (AAS) is used to analyse the amount of copper metal removed.

\subsection{Batch Equilibrium Method}

First, $20 \mathrm{~g}$ of soil samples were mixed in a plastic container containing $500 \mathrm{ml}$ of $1 \mathrm{mg} / \mathrm{l}$ of copper metal solution. Next, the mixture was stirred for two minutes. After a defined time, the copper metal solution was extracted by using filter paper of pore size 1.2 $\mu \mathrm{m}$. Then, the extracted copper metal solution was transferred to an Erlenmeyer flask containing $1 \%$ of $\mathrm{HNO}_{3}$. As the volume of $100 \mathrm{ml}$ is to be used, the amount of extracted copper metal solution and $\mathrm{HNO}_{3}$ in the Erlenmeyer flask was $99 \mathrm{ml}$ and $1 \mathrm{ml}$ respectively. All these steps were performed at lab temperature. Finally, the concentration of copper solution inside the flask was determined by using AAS flame method. Batch method was repeated with three samples for each studied time of 1, 2, 3, 5, 24, 168 and 336 hours to determine its equilibrium time to reach maximum capacity. 


\section{Results and Discussion}

Comparisons of copper metal concentrations at studied time 1, 2, 3, 5, 24, 168 and 336 hours are included. Other than that, data acquired are related and compared to other researchers. The removal efficiency of copper metal solution by wetland soil is also calculated and presented in tables and charts.

\subsection{Concentration of Copper Metal Solution}

After 1 hour of contact time, copper metal solutions were tested using AAS to determine its absorbance value. The concentrations were determined by referring to the standard graph produced by the AAS using standard solutions prepared. Table 1 shows the results obtained. Each studied time of 1, 2, 3, 5, 24, 168 and 336 hours are tested with 3 samples.

Table 1: Concentration of samples after a period of time

\begin{tabular}{|c|c|c|c|}
\hline $\begin{array}{l}\text { Time, } \\
\mathrm{hr}\end{array}$ & Sample & $\begin{array}{l}\text { Copper Concentration, } \\
\mathrm{mg} / \mathrm{l}\end{array}$ & Percentage Removal, \% \\
\hline \multirow{3}{*}{1} & 1 & 0.731 & 26.9 \\
\hline & 2 & 0.800 & 20.0 \\
\hline & 3 & 0.838 & 16.2 \\
\hline \multirow{3}{*}{2} & 1 & 0.717 & 28.3 \\
\hline & 2 & 0.710 & 29.0 \\
\hline & 3 & 0.667 & 33.3 \\
\hline \multirow{3}{*}{3} & 1 & 0.624 & 37.6 \\
\hline & 2 & 0.703 & 29.7 \\
\hline & 3 & 0.587 & 41.3 \\
\hline \multirow{3}{*}{5} & 1 & 0.567 & 43.3 \\
\hline & 2 & 0.676 & 32.4 \\
\hline & 3 & 0.569 & 43.1 \\
\hline \multirow{3}{*}{24} & 1 & 0.581 & 41.9 \\
\hline & 2 & 0.572 & 42.8 \\
\hline & 3 & 0.562 & 43.8 \\
\hline \multirow{3}{*}{168} & 1 & 0.581 & 50.6 \\
\hline & 2 & 0.572 & 50.3 \\
\hline & 3 & 0.562 & 49.7 \\
\hline \multirow{3}{*}{336} & 1 & 0.499 & 50.1 \\
\hline & 2 & 0.501 & 49.9 \\
\hline & 3 & 0.515 & 48.5 \\
\hline
\end{tabular}

Figure 1 below shows the graph of all concentrations and studied time of sample 1, 2 and 3. From the results obtained, we can see that concentration of all samples decreases with time. It shows an intense decrease during the first 0 to 3 hours of contact time, this means the rate of adsorption process occurred during this hour is faster. During the early hour period when soil samples were firs exposed to the copper solution, adsorption process occurred at its peak rate because of abundant site activities. After 5 hours, it starts to slowly decline and finally reaching a constant until 336 hours. This indicates that the maximum capacity had been reached after 168 hours or more of contact time, however, a study performed by Sangiumsak \& Punrattanasin, (2014) said that the equilibrium time of copper adsorption occurred within 6-12 hours. As time goes by, more and more copper metals are being adsorbed into the soil and because heavy metals are non-degradable, it tends to bio-accumulate causing the soil to be saturated and increase in metal concentration (Cataldo \& Wildung, 1978). Therefore at this hour, the wetland soil had reached its maximum capacity of copper metal adsorption. At the end of the graph, we can see that it increases slightly during 336 hours, it is due to desorption occurred as the soil is in equilibrium within the bulk phase (Mosquera-Vivas et al., 2018).

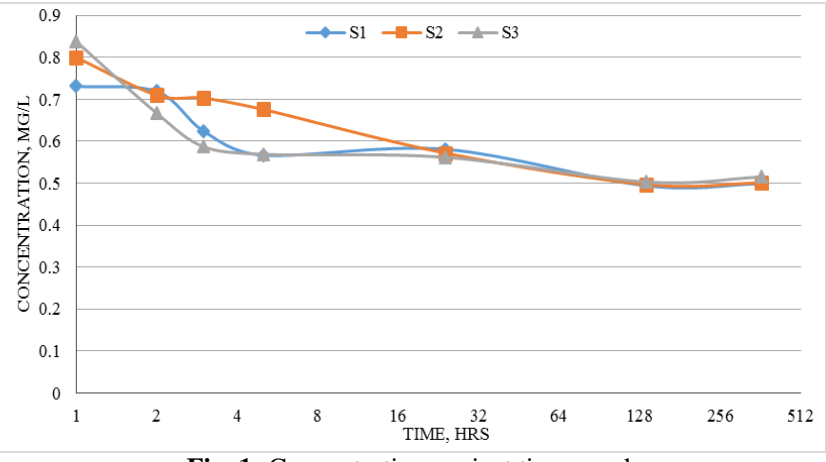

Fig. 1: Concentration against time graph

\subsection{Removal Efficiency of Wetland Soil}

From Table 1 above, we can see that the wetland soil has an increasing percentage removal as the contact time increases. For sample 1 , early stages of contact time ( 0 - 3 hours $)$ has a percentage removal of ranged $26 \%$ to $30 \%$. After that, it increases slightly until reaching a constant of almost $50 \%$ removal efficiency. As for sample 2 and 3, it shows a similar pattern to percentage removal of sample 1, with highest percentage removal of almost $50 \%$. The results are also plotted in Figure 2. For a retention time of 3 hours in wetland, we can assume that it is enough to reach a removal of $30 \%$ copper metal solution in the water. Although the result looks promising, the wetland soil will eventually reach an equilibrium within the bulk phase where adsorption will stop and desorption starts. In order to maintain the effectiveness of wetland soil in the adsorption process, a period of resting is needed for the wetland to regain its function. For now, humans are still very dependent on Mother Nature in this situation.

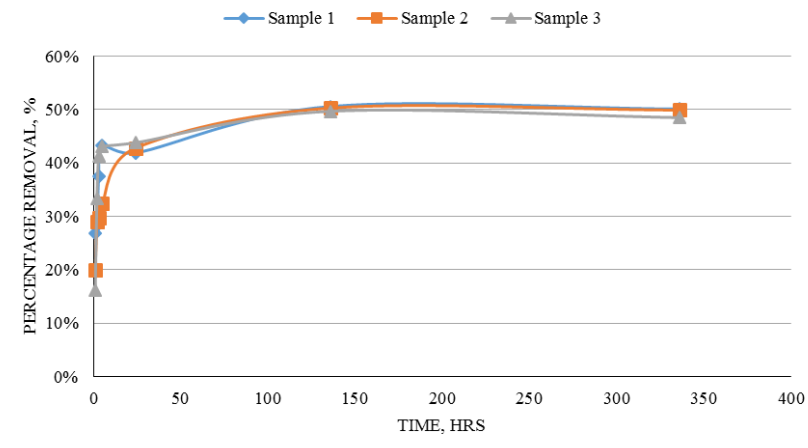

Fig. 2: The percentage removal against time

\section{Conclusion}

In This study investigated the removal efficiency of copper metal solution by wetland soil. We can clearly see from the graph concentration vs time produced, the concentration of copper metal solution decreases gradually and finally coming to a constant. This indicates that the wetland soil had reached its equilibrium time or, in other words, maximum capacity. On the other hand, from the removal efficiency table produced, we can see that all three samples have increasing percentage removal up until the maximum capacity of the soil. In average, the removal efficiency of copper metal solution by wetland soil is about $50 \%$.

\section{Acknowledgement}

This The authors are grateful for the supports from UNITEN and Innovation Research Management Centre (i-RMC) for facilitating this research under UNITEN internal grant (Vot: J510050716). We sincerely thank the anonymous reviewers for giving comments and suggestions which improved this manuscript. 


\section{References}

[1] Cataldo DA, Wildung RE (1978), Soil and plant factors influencing the accumulation of heavy metals by plants. Environmental Health Perspectives, Vol. 27, pp.149-159.

[2] Fronczyk J (2017), Artificial road runoff water treatment by a pilotscale horizontal permeable treatment zone. Ecological Engineering, 107, 198-207.

[3] Gardiner LR, Moores J, Osborne A, \& Semadeni-Davies A (2016), Risk assessment of road stormwater runoff.

[4] Gill LW, Ring P, Higgins NM, \& Johnston PM (2014), Accumulation of heavy metals in a constructed wetland treating road runoff. Ecological Engineering 70, 133-139.

[5] Järup L (2003), Hazards of heavy metal contamination. British Medical Bulletin 68(1), 167-182.

[6] Mosquera-Vivas CS, Martinez MJ, García-Santos G \& GuerreroDallos JA (2018), Adsorption-desorption and hysteresis phenomenon of tebuconazole in Colombian agricultural soils: Experimental assays and mathematical approaches. Chemosphere 190, 393-404.

[7] Nelson EA (2002), Constructed wetlands for removal of heavy metals from NPDES outfall effluent. Savannah River Site (US).

[8] Qasaimeh A, AlSharie H \& Masoud T (2015), A review on constructed wetlands components and heavy metal removal from wastewater. Journal of Environmental Protection 6(07), 710.

[9] Sangiumsak N \& Punrattanasin P (2014), Adsorption Behavior of Heavy Metals on Various Soils. Polish Journal of Environmental Studies 23(3).

[10] Sree AR, Rao BN \& Suresh K (2016), Rectification of Heavy Metal Contaminated Soils using Phytoremediation Process. I-Manager's Journal on Civil Engineering 6(4), 37.

[11] Wang J, Zhang P, Yang L \& Huang T (2015), Adsorption characteristics of construction waste for heavy metals from urban stormwater runoff. Chinese Journal of Chemical Engineering 23(9), $1542-1550$

[12] Yao Z, Li J, Xie H \& Yu C (2012), Review on remediation technologies of soil contaminated by heavy metals. Procedia Environmental Sciences 16, 722-729. 